\title{
Synthesis of benzocyclobutenone containing polymers for UV curable pressure sensitive adhesive applications
}

\author{
Pradeep Iyer,* Kai Li, Prakash Mallya, and Wayne Wang ${ }^{\#}$ \\ Avery Research Center Inc, Avery Dennison Corporation, 2900 Bradley Street, \\ Pasadena, CA 91107-1599 \\ E-mail:pradeep_iyer@averydennison.com
}

\section{Dedicated to Professor P. T. Narasimhan on his $75^{\text {th }}$ birthday}

(received 01 Mar 04; accepted 21 Feb 05; published on the web 02 Mar 05)

\begin{abstract}
Synthesis of novel benzocyclobutenone (BCBO) containing polymers provide for residual-free pressure sensitive adhesives (PSA's) that can be readily UV photo-crosslinked without the need for conventional photoinitiators.
\end{abstract}

Keywords: $\mathrm{BCBO}$, benzocyclobutenone, photopolymerization, PSA, pressure sensitive adhesives, crosslinking, polymer

\section{Introduction}

In the late 1970s, Dow Chemical Company conducted research in the use of benzocyclobutenes in polymer synthesis. This led to the first patent grant that described its use in the preparation of high molecular weight polymers in 1985 . $^{1}$ Since then, the study and application of benzocyclobutene polymers expanded rapidly. $2,3,4,5$

However, the utility of benzocyclobutene polymers have been confined due to the limited modes of inter- and intra-polymer coupling reactions (dimerizations and Diels-Alder cycloadditions) available through the o-quinodimethane intermediate. Hence, dienes predominantly proved to be choice comonomers for use in producing linear thermoplastics. However, other commercial materials, such as diols and diamines, could not be utilized, due to their unpredictable side reactions with the o-quinodimethane intermediate. Applications of this chemistry to vinyl polymers and polyols are also scarce, with a few reports on the modification of polystyrene. Accordingly, an effort was made to study the utility of benzocyclobutenone (BCBO) photolysis. ${ }^{6,7}$

\footnotetext{
\# Department of Chemistry, Carleton University,1125 Colonel By Drive, Ottawa, ON K1S 5B6, Canada
} 
BCBO can be prepared in several ways. ${ }^{8,9,10}$ It is quite different from benzocyclobutene, because it is well known to readily react with alcohols besides undergoing cycloaddition reactions with aldehyde and dienophiles such as maleic anhydride and dimethyl fumarate upon flash photolysis. $\mathrm{BCBO}$ and its derivatives have been reported to undergo a thermal ringopening reaction to form reactive $\alpha$-oxo-o-quinodimethane intermediate that subsequently react with alcohols to yield esters quantitatively. ${ }^{11}$ Furthermore, a similar reaction also proceeds under UV irradiation (see Figure 1). ${ }^{12}$ This reaction is very attractive for many applications including synthesis of pressure sensitive adhesives (PSAs).
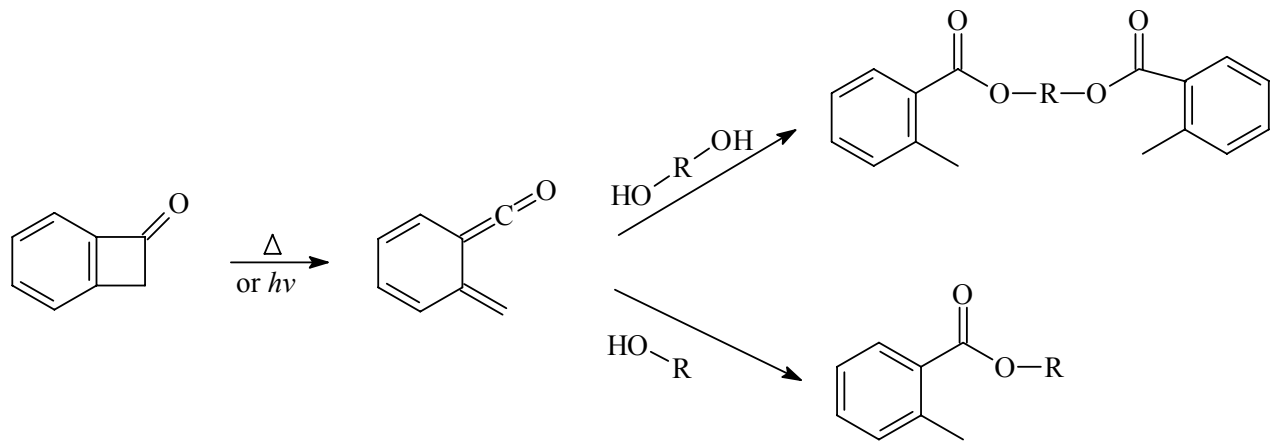

Figure 1. Reactions of BCBO with alcohol.

For most applications, it is desirable to have PSAs that possess high cohesive strength. This desired property is generally incorporated through optimum crosslinking of the adhesive polymers. For solvent-based adhesives, crosslinking is introduced after the polymer synthesis to avoid making high viscosity solutions that are difficult to coat. Post-crosslinking is also commonly employed for water based PSAs and thermally induced through formations of ionic or covalent links. Photoreactive systems are also utilized to obtain covalent crosslinking e.g. using BASF's Acronal DS 3458. In these systems, undesirable residuals from the photoinitiator are left behind after the crosslinking process. In this study, we report the study of applying BCBO functional monomer within pressure sensitive adhesives to achieve UV induced crosslinking to enhance PSA performance without the need for a photoinitiator. 


\section{Results and Discussion}

In order to study the effect of BCBO functional group, low molecular weight adhesive polymers were synthesized. For emulsion polymerization, a chain transfer reagent, $n$-dodecyl mercaptan (n-DDM), was used to control the molecular weight as well as the polymer gel content. The synthesis of BCBO containing emulsion adhesives were conducted according to the general procedure described in the experimental section. A control sample $\boldsymbol{a}$ had the following composition: 2-ethlyhexyl acrylate (2-EHA)/butyl acrylate (BA)/methyl methacrylate (MMA)/ methacrylic acid (MAA)/ acrylic acid(AA)/ 2-hydroxyethyl acrylate (2HEA)/n-DDM with weight ratio at 65.11/14.92/14.92/1.76/2.47/0.54/0.27. BCBO monomer, benzocyclobutenone acrylamide (BCBO-AM), was used in sample $\boldsymbol{b}$ which had the following composition: 2EHA/BA/MMA/MAA/AA/2HEA/BCBO-AM/n-DDM

$(64.77 / 14.84 / 14.84 / 1.76 / 2.45 / 0.54 / 0.54 / 0.27$, wt ratio). The polymers produced in both emulsion systems had broad molecular weight distribution, and low gel contents. Table 1 lists some characterization data of samples $\boldsymbol{a}$ and $\boldsymbol{b}$.

Table 1. Characterization data of polymer $a$ and $b$

\begin{tabular}{cccccc}
\hline $\begin{array}{c}\text { Sample } \\
\text { ID }\end{array}$ & $\begin{array}{c}\text { Dv } \\
(\mathrm{nm})\end{array}$ & Mw & Mn & $\begin{array}{c}\text { Mw/M } \\
\mathrm{n}\end{array}$ & $\begin{array}{c}\text { Gel content } \\
(\%)\end{array}$ \\
\hline $\boldsymbol{a}$ & 179 & $145 \mathrm{~K}$ & $37 \mathrm{~K}$ & 3.91 & 0.9 \\
$\boldsymbol{b}$ & 194 & $143 \mathrm{~K}$ & $38 \mathrm{~K}$ & 3.77 & 1.0 \\
\hline
\end{tabular}

Table 2 shows peel and loop tack for both samples before and after curing. When the UV dosage increased from 0 to ca. $900 \mathrm{~mJ} / \mathrm{cm}^{2}$, a slight drop in 180 peel for sample $\boldsymbol{a}$ was observed; for sample $\boldsymbol{b}$, its peel force reached maximum at the dose rate of ca. $600 \mathrm{~mJ} / \mathrm{cm}^{2}$, with further exposure to UV radiation reducing the peel force. The loop tack values for both samples showed no significant change at different curing levels.

Table 2. $180^{\circ}$ Peel and Loop tack of samples $a \& b$

\begin{tabular}{ccccc}
\hline ID & Dose & $180^{\circ}$ peel & Loop tack & $\begin{array}{c}\text { Failure } \\
\text { Mode* }\end{array}$ \\
\hline & $\left(\mathrm{mJ} / \mathrm{cm}^{2}\right)$ & $(\mathrm{N} / 25 \mathrm{~mm})$ & $(\mathrm{N} / 25 \mathrm{~mm})$ & \\
$\boldsymbol{a} 1$ & 0 & 21.9 & 15.3 & $\mathrm{P}$ \\
$\boldsymbol{a} 2$ & $2 \times 300$ & 9.6 & 14.0 & $\mathrm{P}$ \\
$\boldsymbol{a} 3$ & $3 \times 300$ & 18.8 & 13.1 & $\mathrm{P}$ \\
$\boldsymbol{b} 1$ & 0 & 12.7 & 15.3 & $\mathrm{P}$ \\
$\boldsymbol{b} 2$ & $2 \times 309$ & 20.1 & 14.0 & $\mathrm{P}$ \\
$\boldsymbol{B} 3$ & $3 \times 309$ & 8.3 & -- & $\mathrm{P}$ \\
\hline
\end{tabular}

* P: panel failure 
Both adhesives $\boldsymbol{a}$ and $\boldsymbol{b}$ showed low static shear due to their low gel contents (see Table 1). Without UV irradiation, samples have comparable shears of 7.3 minutes and 11.3 minutes, respectively. For control $\boldsymbol{a}$, no increase in the shear strength was observed with increase in curing intensity. On the contrary, sample $\boldsymbol{b}$ showed dramatic gain in the shear strength when the UV dose changed from 0 to ca. $900 \mathrm{~mJ} / \mathrm{cm}^{2}$. As shown in Table 3, with curing energy of $618 \mathrm{~mJ} / \mathrm{cm}^{2}$, the static shear for $500 \mathrm{~g}$ load was over nineteen days! By increasing the load to $1 \mathrm{~kg}$, the shear strength was 49 hours for sample cured with $2 \times 309 \mathrm{~mJ} / \mathrm{cm}^{2}$, and 88 hours for that cured with $3 \times 309 \mathrm{~mJ} / \mathrm{cm}^{2}$.

Table 3. Shear tests of $a$ and $b$ with UV curing

\begin{tabular}{ccccc}
\hline & $\begin{array}{c}\text { Dose } \\
\text { ID }\end{array}$ & \multicolumn{2}{c}{ Static Shear (minutes) } & Failure \\
\cline { 3 - 4 } & $\left(\mathrm{mj} / \mathrm{cm}^{2}\right)$ & $0.5 \mathrm{~kg}$ & $1 \mathrm{~kg}$ & Mood* $^{*}$ \\
\hline & & $(\mathrm{min})$ & $(\mathrm{min})$ & \\
$\boldsymbol{a} 1$ & 0 & 7.3 & -- & $\mathrm{C}$ \\
$\boldsymbol{a} 2$ & $2 \times 300$ & 7.8 & -- & $\mathrm{C}$ \\
$\boldsymbol{a} 3$ & $3 \times 300$ & 7.7 & -- & $\mathrm{C}$ \\
$\boldsymbol{b} 1$ & 0 & 11.3 & -- & $\mathrm{C}$ \\
$\boldsymbol{b} 2$ & $2 \times 309$ & 19 days & 49 hours & $\mathrm{C}$ \\
$\boldsymbol{B} 3$ & $3 \times 309$ & 19 days & 88 hours & $\mathrm{C}$ \\
\hline
\end{tabular}

C: cohesive failure.

The increase in the shear strength upon UV radiation is due to the reaction of BCBO unit with $-\mathrm{OH}$ or another $\mathrm{BCBO}$ unit in the polymer chains. It was confirmed that the curing reaction was not affected by factors like oxygen or moisture content as conventional photreactions are!

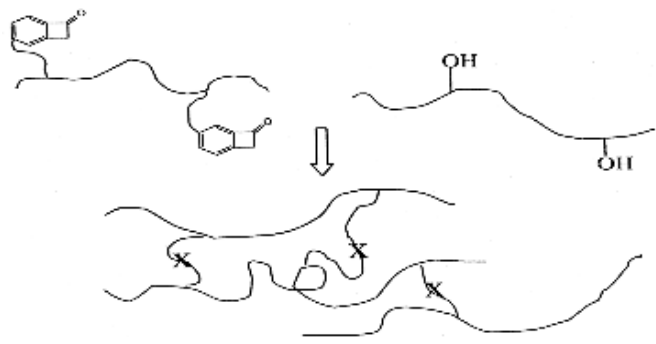

Figure 2. UV crosslinking BCBO solvent PSA.

A solvent borne adhesive containing $\mathrm{BCBO}$ was also examined. In this case, adhesive polymers containing hydroxyl and $\mathrm{BCBO}$ functional groups were made, respectively. When a mixture of the two is coated, and cured under UV, the cohesive strength of the adhesive from the 
mixture is expected to be superior due to the $\mathrm{BCBO}$ induced crosslinking between the individual polymers, as outlined in Figure 2.

Accordingly, polymers containing 2-hydroxyl ethyl acrylate $(\boldsymbol{c})$ and $\mathrm{BCBO}(\boldsymbol{d})$ were synthesized by solution polymerization, and polymer $\boldsymbol{e}$ was produced by mixing $\boldsymbol{c}$ and $\boldsymbol{d}$ at $1: 1$ weight ratio. Polymer $\boldsymbol{e}$ was coated on a 2 mil PET release liner, which was dried in an oven at $66^{\circ} \mathrm{C}$ for $10 \mathrm{~min}$. The dried adhesive was then exposed to UV irradiation. The cured adhesive was laminated to a BOPP facestock, which allowed the adhesive to be transferred from the release liner to the facestock. The coat weight of adhesive (dry weight) was $40 \mathrm{~g} / \mathrm{m}^{2}$. Adhesive performance data is presented in Table 4 .

Table 4. Solvent adhesive performance

\begin{tabular}{ccccc}
\hline ID & $\begin{array}{c}\text { Dose } \\
\left(\mathrm{mj} / \mathrm{cm}^{2}\right)\end{array}$ & $\begin{array}{c}180^{\circ} \text { peel } \\
(\mathrm{N} / 25 \mathrm{~mm})\end{array}$ & $\begin{array}{c}\text { Loop tack } \\
(\mathrm{N} / 25 \mathrm{~mm})\end{array}$ & $\begin{array}{c}\text { Static shear } \\
@ 0.5 \mathrm{~kg} \\
(\mathrm{~min})\end{array}$ \\
\hline $\boldsymbol{e}$ & 0 & -- & -- & $<1$ \\
$\boldsymbol{e}$ & 900 & 25.0 & 21.8 & 230 \\
\hline
\end{tabular}

\section{Experimental Section}

Monomer synthesis. N-benzocyclobutenone acrylamide (I) was synthesized from 5aminobenzocyclobutenone that is derived from benzocyclobutenone by simple nitration and subsequent reduction in high yields. ${ }^{13}$ Synthesis of Monomer I has been described in detail as Example 20 in the same patent ${ }^{13}$ and used as such in the polymer syntheses.

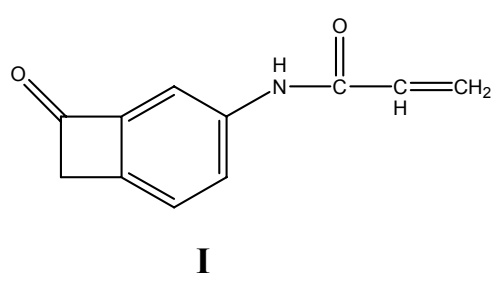

Synthesis of emulsion adhesives. An emulsion adhesive containing no BCBO functional groups was prepared by emulsion polymerization from a plurality of monomers consisting of $65.11 \% 2$ ethylhexyl acrylate (2-EHA), 14.92\% butyl acrylate (BA), 14.92\% methyl methacrylate (MMA), $1.76 \%$ methacrylic acid (MAA), 2.47\% acrylic acid (AA), and $0.54 \%$ 2-hydroxyethly acrylate (2-HEA), based on the weight of all monomers, with $0.27 \%$ by weight of $n$-dodecylmercaptan (n-DDM) added as a chain transfer agent. A 1-liter, jacketed, cylindrical reaction flask equipped with a four-neck flask head was fitted with a steel stirring rod with multiple steel blades, a reflux 
condenser, a thermometer, and a nitrogen inlet tube. The stirring speed was set at ca. $125 \mathrm{rpm}$, and the reaction temperature was set at $80^{\circ} \mathrm{C}$.

A reactor pre-charged solution was made by dissolving $1.2 \mathrm{~g}$ of Disponil FES-32 (32\% solids, manufactured by Henkel) surfactant in $100 \mathrm{~g}$ deionized (DI) water.

A pre-emulsion feed soap solution was formed by dissolving $0.39 \mathrm{~g}$ Aerosol OT75 (75\% solids), $5.53 \mathrm{~g}$ Igepal CO-887 (70\% solids), $2.31 \mathrm{~g}$ Disponil FES-32 and $105 \mathrm{~g}$ DI water.

A monomer mix was made up with $240 \mathrm{~g}$ 2-ethylhexyl acrylate, $55 \mathrm{~g}$ of n- butyl acrylate, $55 \mathrm{~g}$ of methyl methacrylate, $6.5 \mathrm{~g}$ of methacrylic acid, $9.1 \mathrm{~g}$ of acrylic acid, $2.0 \mathrm{~g}$ of 2-hydroxyl ethyl acrylate, and $1 \mathrm{~g}$ of $\mathrm{n}$ - dodecyl mercaptan. The monomer mix was added to the preemulsion solution under stirring for $10 \mathrm{~min}$.

An initiator solution A was prepared by dissolving $0.74 \mathrm{~g}$ FES-32, $1.79 \mathrm{~g}$ Igepal CO-887 and $0.5 \mathrm{~g}$ potassium persulfate (KPS) in $67 \mathrm{~g}$ of DI water; solution B was made by dissolving $0.5 \mathrm{~g}$ of KPS in $67 \mathrm{~g}$ of DI water. A kickoff initiator solution was prepared by dissolving $0.75 \mathrm{~g}$ of KPS in $38 \mathrm{~g}$ of water.

The reactor pre-charged solution was introduced to the glass reactor, which was flushed with nitrogen. The kickoff initiator solution was added when the solution temperature reached $80^{\circ} \mathrm{C}$. After $5 \mathrm{~min}, 20 \mathrm{~g}$ of the pre- emulsion solution was introduced into the reactor. Upon observing polymerization, the pre-emulsion solution and initiator solution A feeds were started. Initiator solution B was fed at the end of solution A. The pre-emulsion solution feed was completed in 3 hr period, and the initiator solution $\mathrm{A}$ and $\mathrm{B}$ feeds were completed in $3 \mathrm{hr}$ and $15 \mathrm{~min}$. Polymerization continued for another $30 \mathrm{~min}$ after completion of the initiator solution B feed. The polymerization temperature was maintained at $80{ }^{\circ} \mathrm{C}$. during the polymerization. Polymerization of the monomer mixture yielded a polymer latex, which can be coated on a substrate.

The procedure used to prepare polymers containing $\mathrm{BCBO}$ acrylamide (BCBO-AM) entailed using a mixture consisting of 2-EHA/ BA/ MMA/ MAA/ AA/ 2-HEA/ BCBO-AM/n-DDM and their respective weight percentages are 64.77/14.84/14.84/1.76/2.45/0. 54/0.54/0.27.

Synthesis of solvent borne adhesives. A UV-cured, transfer-coated solvent borne adhesive was prepared as follows:

Polymer Synthesis: A) $19.17 \mathrm{~g}$ of 2EHA, $1.87 \mathrm{~g}$ of AA, $5.85 \mathrm{~g}$ of MA, and $0.23 \mathrm{~g}$ of 2HEA were mixed in $40.69 \mathrm{~g}$ of ethyl acetate. The mixture was placed in a glass bottle reactor. After adding $0.678 \mathrm{~g}$ of Vazo 64 initiator, the mixture was purged with nitrogen for $5 \mathrm{~min}$. The sealed reactor was then put into an oil bath, and the reaction temperature was set at $70^{\circ} \mathrm{C}$. Polymerization proceeded for 16 hours.

B) A BCBO-containing polymer was synthesized in the same manner as described in A), except that $1.87 \mathrm{~g}$ of $\mathrm{BCBO}$ acrylamide monomer was used instead of 2-HEA.

Transfer-Coated Adhesive Preparation: A mixture of A and B at a 1/1 ratio was prepared and coated on a 2 mil PET release liner. The coated polymer solution was dried in an oven at $66^{\circ} \mathrm{C}$. for $10 \mathrm{~min}$, and the dried adhesive was then exposed to UV irradiation. The cured adhesive was 
laminated to a BOPP facestock, which allowed the adhesive to be transferred from the release liner to the facestock. The coat weight of adhesive (dry weight) was $40 \mathrm{gms} / \mathrm{m}^{2}$.

Characterization. For solution and emulsion adhesives, $\mathrm{Mn}$ and $\mathrm{Mw}$ were analyzed by Gel Permeation Chromatography using a Waters 2690 Alliance system with a refractive index detector. For emulsion polymers, the gel content was measured by the following procedure: a known amount of dry adhesive was placed in a 10 micron polytetrafluoroethylene membrane filter. The edges of the membrane were sealed to contain the sample, and the filter was placed in a $20 \mathrm{ml}$ vial containing THF. The vial was then tumbled for 24 hours for the soluble portion to be extracted. The filter was taken out, dried at elevated temperature under vacuum and re-weighed to determine the percent insoluble (gel content) residue remaining.

Adhesive constructions were prepared by coating the adhesives onto a 2 mil Mylar or BOPP facestocks, which was laminated to a silicone-coated release liner. The adhesive coat weight was controlled at $22 \mathrm{~g} / \mathrm{m}^{2}$. Adhesive peel, static shear tests and loop tack were conducted. The adhesion tests of $180^{\circ}$ peel (Pressure Sensitive Tape Council Test Method No. 1), loop tack (FINAT Test No. 9), and shear tests were examined using standard methodologies.

Post $\mathrm{BCBO}$ induced crosslinking of the adhesives was introduced by UV curing. The UV spectral outputs from either "D" or " $H$ " Mercury bulb lamps equipped on a UV Fusion system was used. For line speed of 0.363 meters $/ \mathrm{sec}$, the dose was $309 \mathrm{~mJ} / \mathrm{cm}^{2}$ for one pass.

\section{Conclusions}

Benzocyclobutenone acrylamide monomer has been incorporated into polymers for PSA applications. UV radiation of the obtained adhesive showed that BCBO functional groups are capable of effectively crosslinking the adhesives. No photoinitiator is needed in such systems. The usefulness of this functional monomer can be readily extended to afford acrylic warm melts, hybrid PSAs, and protective coatings.

\section{References and Notes}

1. Kirchhoff, R. A. U. S. Pat. 4,540,763, 1985.

2. Tan, L. S.; Arnold, F. E. U. S. Pat. No. 4,711,964, 1987.

3. Kirchhoff, R. A.; Carriere, C. J.; Bruza, K. J.; Rondan, N. G.; Sammler, R. L. J. Macromol. Sci. Chem. 1991, A28, 1079.

4. Tan, L. S.; Arnold, F. E. J. Polym. Sci., Part A: Polym. Chem. 1988, 26, 1819.

5. Kirchhoff, R. A.; Bruza, K. J. Chemtech 1993, 22.

6. Suzzarini, L.; Lin, J.; Wang, Z. Y. Tetrahedron Lett. 1998, 39, 1695.

7. Wang, Z. Y.; Kuang, L.; Meng, X. S.; Gao, J. P. Macromolecules 1998, 31, 5556.

8. Spangler, J.; Kim, J. H. Tetrahedron Lett. 1972, 11, 1249. 
9. Hedaya, E.; Kent, M. E. J. Am. Chem. Soc. 1970, 92, 2149.

10. Liebeskind, L. S.; South, M. S. J. Org. Chem. 1982, 47, 3815.

11. Wang, Z. Y.; Suzzarini, L.; Gao, J. P. Tetrahedron Lett. 1997, 38, 5745.

12. Wang, Z. Y. et al., $82^{\text {nd }}$ Canadian Society for Chemistry, Toronto, 1999.

13. Wang, Z. Y. U. S. Pat. 5,869,693, 1999. 